\title{
Eight Democratic Parties in China
}

\author{
Huang Xiaoyi \\ Correspondence: Huang Xiaoyi, Democratic Parties History Museum of China, NO. 35, Dongcun, JialingBridge, \\ Shangqingsi, Chongqing, China.
}

Received: February 2, 2021 Accepted: March 2, $2021 \quad$ Online Published: March 11, 2021

doi:10.11114/ijecs.v4i1.5187 URL: https://doi.org/10.11114/ijecs.v4i1.5187

\begin{abstract}
China has eight democratic parties which established cooperative relations with the CPC. All the democratic parties earnestly performed the functions of participating in and deliberating on state affairs and exercising democratic supervision in China's political life. Their participation in state affairs under the leadership of the CPC is a major indication of people's democracy. They are of great importance to enhance and develop the multi-party cooperation and political consultation system under the leadership of the CPC. This paper introduces the establishing time, the mainly component members, the founding background, the history evolution and the outstanding contributions of China's eight democratic parties.
\end{abstract}

Keywords: Politic, China, CPC, Democratic Party

\section{Introduction}

The eight democratic parties of China are friendly parties that "coexist over a long period of time, engage in mutual supervision, show utter devotion to each other, and share honor and disgrace, weal and woe" with the CPC. The eight democratic parties participate in and deliberate on state affairs. The inherent requirements of the people's democratic dictatorship and the actual role played by the eight democratic parties in China's political life determine their role as participating parties. This paper gives a systematic introduction to China's eight democratic parties.

\section{The Revolutionary Committee of Chinese Kuomintang}

\subsection{Basic Introduction}

The Revolutionary Committee of Chinese Kuomintang(RCCK for short) was founded on January 1,1948,Hongkong, comprising members from the Three Peoples Principles Comrades' Federation, the Chinese KMT Association for Promoting Democracy and other patriotic democrats. The successive chairpersons of the RCCK in the past were $\mathrm{Li}$ Jishen, He Xiangning, Zhu Yunshan, Wang Kunlun, Qu Wu, Zhu Xuefan, Li Peiyao, He Luli, Zhou Tienong.The present chairman is Wan Exiang

\subsection{History Evolution}

The RCCK, which was organized by KMT's patriotic democratic personages has a profound historical origin with the KMT. In 1924, at the First National Congress of the KMT, Dr. Sun Yat-sen gave another explanation to the Three Principles ,added the policies of the alliance with Russia, the cooperation with the CPC and the assistance to the farmers and workers, thus, First Cooperation Between the KMT and CPC was formed. in 1925, Dr. Sun Yat-sen passed away. The differentiations among KMT's Leftists, Centrists and Rightists were increasingly fierce. KMT's Leftists, represented by Song Qingling and Liao Zhongkai persisted in carrying forward the spirit of Dr.Sun Yat-Sen's Three People's Principles, but KMT's Rightists strongly opposed them and provoked the Apr. 12th Incident and the July 15th Incident. Under these circumstances, KMT's Rightists launched the Nanchang Uprising together with the CPC.

After the "September 18th Incident" broke out in 1931, Chiang Kai-shek pursued the policy of "Resisting Foreign Aggression after Stabilizing the Country". In 1933, Jiang Guangnai and Cai Tingkai, generals of the 19th Route Army led the Fujian Incident with Li Jishen . The KMT's Leftists raised the banners of anti-Japanese and anti-Chiang.

In the late period of the Anti-Japanese War, in order to end Chiang's dictatorship and one-party autocracy and form a coalition government, on October 28, 1945, the Three Peoples Principles Comrades' Federation was established in Teyuan, Shangqingsi, Chongqing. In April 1946, China Kuomintang Association for Promoting Democracy was established in Guangzhou. 
In order to unite KMT's patriotic democratic forces as soon as possible, the Revolutionary Committee of Chinese Kuomintang was established on January 1, 1948 in Hongkong.

\subsection{Contributions}

After the founding of New China, under the leadership of the CPC, the RCCK actively engaged in land reform movement, Resist-America-Aid-Korea Campaign , the movement against the "three evils" and the "five evils" ,making unremitting efforts to reinforce people's democratic dictatorship and promote the recovery and development of the national economy.

Since reform and opening-up, by actively promoting economic and cultural exchanges between Mainland and Taiwan, the RCCK has made great contribution to the reunification of the motherland.

\section{The China Democratic League}

\subsection{Basic Introduction}

The China Democratic League (CDL for short). Comprising mainly senior and middle intellectuals in the fields of culture, education, science and technology, the CDL was secretly established on March 19th, 1941 in Teyuan, Shangqingsi. The successive chairpersons of the CDL in the past were Huang Yanpei, Zhang Lan, Shen Junru, Yang Mingxuan, Shi Liang, Hu Yuzhi, Chu Tunan, Fei Xiaotong, Ding Shisun, Jiang Shusheng, Zhang Baowen.The present chairman is Ding Zhongli. It has the existing members of more than 224,000 across the country.

\subsection{History Evolution}

As a Party with a long history, the China Democratic League changed its name for three times to adapt to revolutionary tasks at different periods. After the Anti-Japanese War broke out, the contradiction between the CPC and the KMT aggravated. In order to promote unity and resistance, some democratic personages, which represented by Huang Yanpei and Zhang Lan, established the United Fellowmen Society for National Construction in September 1939 in Chongqing. After the South Anhui Incident, the collaboration between the CPC and the KMT was about to break down, the Anti-Japanese National United Front was at a time of crisis. Under these circumstances, the China Democratic Political League, with the participating of Three Parties and Three Factions was secretly established in March 1941 in Teyuan, Shangqingsi, Chongqing. In September 1944, the China Democratic Political League held a national congress in Chongqing and decided to rename itself the China Democratic League.

\subsection{Contributions}

After the founding of New China, the CDL persists in multi-party cooperation and political consultation system led by the CPC, takes an active role in the construction of national politics, economy and culture, further developing the function of the party participating in the management of state affairs, and sustaining the leadership of the CPC and the socialism, and thus makes great contributions to promoting the opening up policy and economic construction.

\section{The China Democratic National Construction Association}

\subsection{Basic Introduction}

Comprising mainly middle and high-ranking intellectuals in economic circle, the China Democratic National Construction Association (CDNCA for short) was established in the Southwest Industry Mansion, White Elephant Street, Chongqing. The successive chairpersons of the CDNCA in the past were Huang Yanpei, Hu Juewen, Sun Qimeng, Cheng Siwei, Chen Changzhi. The present chairman is Hao Mingjin .There are more than 110,000existing members of across the country.

\subsection{History Evolution}

After the outbreak of the Anti-Japanese War, in order to protect the national industry and commerce and provide military supplies, some businessmen moved their factories from the coastal areas to Sichuan. However, the National Government established monopoly control on those enterprises by its political and military privileges, a large number of private enterprises had been gobbled up, industrialists and businessmen were getting into troubles. It was then that they realized only by forming their own party organization can their rights and interests be protected. In addition, Mao Zedong proposed the policy of protecting the national industry and commerce at the Seventh National Congress of the CPC. Since then, the China Democratic National Construction Association, initiated by Huang Yanpei, Hu Juewen, Zhang Naiqi was established by a number of patriotic industrialists and business people in the Southwest Industry Mansion, White Elephant Street, Chongqing.

\subsection{Contributions}

After the founding of New China, the CNDCA actively participated in the recovery and development of the national economy. Especially in War to Resist U.S. Aggression and Aid Korea, the CDNCA actively organized its memberships 
to donate airplanes and artilleries to the CPC, made great contributions to the victory of War to Resist U.S. Aggression and Aid Korea.

Since reform and opening-up, performing its functions of democratic supervision, and actively engaging in the programme of intellectual poverty alleviation and non-public economy development, the CDNCA has made great contributions to the economic development, political stability and social progress.

\section{The China Association for Promoting Democracy}

\subsection{Basic Introduction}

The China Association for Promoting Democracy(CAPD for short)is a political party comprising mainly intellectuals in the fields of education, culture and publishing.The CAPD was founded in Shanghai on December 30, 1945. The successive chairpersons of the CAPD in the past were Ma Xulun, Zhou Jianren, Ye Shengtao, Lei Jieqiong, Xu Jialu, Yan Juanqi. The present chairman is Cai Dafeng. As of 31, December 2010, there are more than 127,000 existing members across the country.

\subsection{History Evolution}

After the victory of the War of Resistance Against Japan, the dictatorship of KMT aroused public indignation in Shanghai, personages in the fields of culture, education and publishing represented by Ma Xulun and patriots in the business community represented by Wang Shaoao joined together to initiate the China Association for Promoting Democracy in the Science Society of China, Shanghai on December 30,1945 to develop the spirit of democracy and boost the political and democratic practices in China.

After the CAPD was founded, it actively engaged in the patriotic democratic movements against civil war and autocracy and organized a peace petition mission to go to Nanjing to appeal for peace, however, when the mission arrived at Xia guan station, they were badly beaten up by the spies of the KMT, this incident has been known as the Xiaguan Massacre in Chinese history.

\subsection{Contributions}

In initial stage of new China, the CAPD played a very positive role in the establishment and the development of new china's education, culture and publication.

Since reform and opening-up, Chinese history turned over a new leaf and the democracy stepped into a new developing stage after the founding of New China. Since the First National Congress of the CAPD was held, the CAPD has taken an active role in strengthening the state power of the people's democratic dictatorship, recovering national economy, activating the political life, and developing socialist revolution and construction in the fields of establishing and developing education, culture, and the publishing of New China. Abiding by the principle put forward by the CPC of "coexisting over a long period of time and engaging in mutual supervision", the CAPD spares no effort to shift the intellectuals' thought and promote the cooperation between the CAPD members and the labors for more contributions. In 1981, the CAPD proposed to establish Teacher's Day for the first time and on January 21, 1945, at the Sixth National People's Congress agreed to the motion on the establishment of Teacher's Day, decided September 10 as Teacher's Day.

\section{The Chinese Peasants and Workers Democratic Party}

\subsection{Basic Introduction}

The Chinese Peasants and Workers Democratic Party (CPWDP for short) is a political alliance mainly comprising middle-level and senior intellectuals in the medical field of representatives from the field of environmental protection and population resources, it was established in Shanghai on August 9, 1930. The successive chairpersons of the CPWDP in the past were Deng Yanda, Huang Qixiang, Zhang Bojun, Ji Fang, Zhou Gucheng, Lu Jiaxi, Jiang Zhenghua, , Sang Guowei, the present chairman is Chen Zhu. As of 9, August 1930, it has had the existing members of more than 110,000 across the country.

\subsection{History Evolution}

The Chinese Peasants and Workers Democratic Party is the first established Democratic Party in China with a long history.

In 1927, Chiang Kai-shek and Wang Jingwei provoked the Apr. 19th Incident and the July 15th Incident. Deng Yanda, the leader of the left wings of the KMT persisted in carrying forward the spirit of Dr.Sun Yat-Sen's Three People's Principles of "the alliance with Russia, the cooperation with the CPC, the assistance to the farmers and workers". On August, 9, 1930, The Provisional Action committee of the KMT of China was officially established in Shanghai. The anti-Chiang movements led by Deng Yanda aroused the hatred of Chiang Kai-shek, so Chiang offered a reward of 
300,000 for the capture of Deng Yanda. On August, 17, 1931, Deng Yanda was betrayed by a traitor and was arrested in Shanghai, in the same year on November 29, he was secretly killed in Nanjing at the age of 36.

After Deng's sacrifice, all the Party affairs were chaired by KMT Army General Huang Qixiang. On November 20,1933, Huang Qixiang ,together with the generals of KMT's 19th Route Army Chen Mingshu, Cai yankai and some antiChiang forces established the Central People's Government of the Republic of China in Fujian and declared publicly to oppose Chiang Kai-shek and fight against Japan, therefore, Chiang dispatched a large number of armed forces to attack Fujian, people in Fujian rose up to resist, but failed because of the power disparity, this was known as the "Fujian Incident". After the failure of the "Fujian Incident", some leaders of The Provisional Committee went to Hongkong from Fuzhou to do the reconstruction work of their organization.

On November 10, 1935, the Provisional Action Committee of the KMT of China renamed its name as The Action Committee for National Liberation. On February 3, 1947, it was again renamed The Chinese Peasants and Workers Democratic Party.

\subsection{Contributions}

Since the new period, by constantly strengthening the self-development and working persistently towards a new economic landscape, the CPWDP takes an active part in the activities of the CPPCC at various levels. With incomplete estimation, more than60,000 issues having been submitted, the CPWDP central and local organizations have made important contributions to the development of our economy, culture, society, and especially to the medical and health work.

\section{The China Zhi Gong Dang}

\subsection{Basic Introduction}

The China Zhi Gong Dang(CZGD for short), comprises returned overseas Chinese, their relatives, and noted figures and scholars who have overseas ties. The CZGD was founded on October10, 1925 in San Francisco, USA. The successive chairpersons of the CZGD in the past were Chen Jiongming, Li Jishen, Chen Qiyou, Huang Dingcheng, Dong Yanchu, Luo Haocai, the present chairman is Wan Gang. As of 2011, it has had more than 30,000 members.

\subsection{History Evolution}

The China Zhi Gong Dang is the only democratic party established overseas, it derives from the overseas "Hongmen", "Hongmen" is one of the secret organizations with the nature of anti-Qing Dynasty, during the 18th century, branches of the Hongmen were formed overseas and provided financial support for Sun Yat-sen's earlier revolutionary activities. Situ Meitang, a patriotic overseas leader brought forward the assertion to establish a political party of Overseas Chinese in 1920 and The China Zhi Gong Dang was officially founded in San Francisco on October 10,1925, which was one of the overseas Chinese societies. After its establishment, it actively participates in the anti-Japanese and national salvation movement, during the anti-Japanese War, it is estimated that about hundreds of millions of dollars have been donated by Chinese overseas in USA, making immense contributions to the victory of the anti-Japanese war. In May 1947, the party held its third congress in Hong Kong, and made decision to join the People's Democratic United Front, and since then, the CZGD took the road of struggling together and cooperating sincerely with the CPC.

\subsection{Contributions}

The CZGD has earnestly performed the functions of participating in and deliberating on state affairs and exercising democratic supervision, thus making its work more extensive, thorough, and dynamic. The CZGD is greatly involved in the modernization and democratization of the CPC and the state's strategic decision, as the only democratic party which can establish diplomatic ties with other countries, it actively launches get-togethers for the overseas Chinese and compatriots of Hong Kong, Macao, Taiwan and has achieved remarkable success in promoting friendly relationships with other countries as well as the unification of China.

\section{Jiusan Society}

\subsection{Basic Introduction}

The Jiusan Society, comprising mainly the top and intermediate intellectuals in the fields of science and technology, was established on May 4th 1946.The former chairmen of Jiusan Society were Xu Deheng,Zhou Peiyuan,Wu Jieping, Han Qide, the present chairman is Wu Weihua. Up to now, it has had over100, 000 members.

\subsection{History Evolution}

The Democracy and Science Symposium, whose objectives were democracy and science for developing the spirit of patriotism of the May $4^{\text {th }}$ Movement advocated by a number of progressives was renamed Jiusan Society, which was officially founded in Chongqing on May 4th 1946 to commemorate the victory of the Anti-Japanese Warand the Second 
World War.

\subsection{Contributions}

After the founding of new China, the Jiusan society made CPPCC Common Guiding Principles as its political guiding principle. Under the leadership of the CPC, the Jiusan society participated in the arranging of the important affairs in political life and made contributions for the development of scientific technology, education, medical and health etc. As of June 30th 2010,over 218 members from Jiusan society had been elected as the academicians of the Chinese Academy of Sciences and the Chinese Academy of engineering .Some members such as Wu Jieping and Wang Xuan were elected as the academician in both two academies.

Entering a new period, focusing on the central task of economic construction, and developing talent advantage fully which was oriented towards social needs, the Jiusan society has been playing an active role in political participation and democratic supervisions.

\section{Taiwan Democratic Self-Government League}

\subsection{Basic Introduction}

Taiwan Democratic Self-government League (TDSL for short), comprising Taiwanese who were settled down in the mainland, was founded on November $12^{\text {th }} 1947$ in HongKong .The successive chairpersons of the TDSL in the past were Xie Xuehong, Cai Xiao, Su Ziheng, Lin Shengzhong, Cai Zimin, Zhang Kehui, Lin Wenyi, the present chairman is Su Hui.

\subsection{History Evolution}

After the liberation of Taiwan, the KMT was in power, the government implemented the policy of political dictatorship and economy pillage. On February 27th 1947, Anti-tobacco smuggling polices beat the smoke sellers, and killed the onlookers by mistake, a political movement demanding for democracy, known as the February 28 Uprising was launched by the Taiwan people. Due to the failure of the uprising, a number of Taiwan personages engaged in this patriotic campaigns, moved to Hong Kong to continue the struggle against KMT hegemonic-party autocracy. With the help and support of the CPC, the TSL was founded in Hong Kong on November $12^{\text {th }} 1947$, which aims to "accomplish the Taiwan democratic and self-government". In April1948, the CPC raised the issue of holding a new political consultative conference to establish a democratic coalition government. Responding enthusiastically, the TSL expressed its will to "support the issue by the CPC" and "to accelerate the founding ofNew China".

\subsection{Contributions}

Guided by the theory of Deng Xiaoping ,the TDSL earnestly performs its duty as a participating party and plays the role of participation in politics and democratic supervision, supports the policy of the CPC about peaceful reunification of the motherland, opposes any activities aimed at splitting the motherland and sabotaging national unity. With the further development of the reform and opening-up in the mainland, TDSL unites its member and Taiwan compatriots, makes efforts for socialist modernization construction and the reunification of motherland.

In 2008, the central committee of the TDSL proposed "a few suggestions about building the economic zone across the Taiwan Strait". It offered some suggestions to promote the economic development on both sides of the Straits. In order to impel the Taiwan investments moving westward, a fulcrum must be found in the mainland, and this fulcrum is Chongqing. In 2009, the present chairman Lin Wenyi visited Chongqing with a team, signed an agreement about the westward moving of the Taiwan investment with Chongqing Municipal People's Government.

Taiwan and the main land shares the same culture and ancestors , the TDSL gives full play of its superiority to develop the exchange of economy, culture and other aspects between Taiwan and the main land and promote the peaceful reunification of the motherland .There are some examples: 1.culture of Matsu, for promoting the communication of people on both sides of the straits, the central communist committee of TDSL hold some activities about the culture of Matsu ,Zhang Kehui ,the former chairman of TDSL, is the association for promoting exchange the culture of Matsu. 2. Panda tuantuan and yuanyuan went to Taiwan, this suggestion was proposed by Zhang Huajun, who is the general secretary of the central committee of TDSL. 3. The films Once upon a Time in Taiwan and The Knot,which were rewritten from the former chairman Zhang Kehui’s literary works have won the Huabiao Film Awards.

\section{Conclusion}

In the new period, eight democratic parties in China still persist in the system of multi-party cooperation and political consultation led by the CPC and further developing the function of the party participating in the management of state affairs, and sustaining the leadership of the CPC and the socialism, and thus make great contributions to China's economic construction and modernization. The CPC maintains wide political cooperation with the democratic parties and unites with them in the march forward. 


\section{References}

Li, H., Liu, H. P., \&Guo, X. L. (2011).The Brief Introduction of The Democratic Parties History Museum of China. Chongqing: Chongqing Press,2011.

Li, H., Zhang, Y. J., \&Xiong, Y. R. (2011). The Commentaries of The Democratic Parties History Museum of China. Chongqing: Chongqing Press,2011.

Wang, Y. F.(2005). History Evolution of Chinese Democratic Party. Social Scientist(J), 2005(5), 193-196.

Xue, Q. L., \&Li, Y. (2001). History of China's Democratic Parties(The Jiusan Society). Shijiazhuang:Hebei People's Press,2001.

Xue, Q. L., \&Liu, Y. Q. (2001). History of China's Democratic Parties(The China Association for Promoting Democracy). Shijiazhuang:Hebei People's Press,2001.

Xue, Q. L., \&Peng, X. F. (2001). History of China's Democratic Parties(The China Zhi Gong Dang). Shijiazhuang:Hebei People's Press,2001.

Xue, Q. L., \&Tong, X. S. (2001). History of China's Democratic Parties(Taiwan Democratic Self-government League). Shijiazhuang:Hebei People's Press, 2001.

Xue, Q. L., \&Wang, Z. S. (2001). History of China's Democratic Parties(The Revolutionary Committee of Chinese Kuomintang).Shijiazhuang:Hebei People's Press,2001.

Xue, Q. L., \&Yang, R. H. (2001). History of China's Democratic Parties(the China Democratic National Construction Association). Shijiazhuang:Hebei People's Press,2001.

Xue, Q. L., \&Zhang, L. (2001). History of China's Democratic Parties(The Chinese Peasants and Workers Democratic Party). Shijiazhuang:Hebei People's Press,2001.

Xue, Q. L., Zhang, X. M., \&Zhou, J. K. (2001). History of China's Democratic Parties(The China Democratic League). Shijiazhuang:Hebei People's Press,2001.

Zhang X. S. (2006). Basic Features of Chinese Democratic Parties.Journal of Changchun Communist Party Institute, 2006(5), 46-49.

\section{Copyrights}

Copyright for this article is retained by the author(s), with first publication rights granted to the journal.

This is an open-access article distributed under the terms and conditions of the Creative Commons Attribution license (http://creativecommons.org/licenses/by/4.0/). 